\title{
A FORTUNA CRÍTICA DA OBRA DE DÍAZ CASTRO
}

\section{María Xesús Nogueira Universidade de Santiago de Compostela}

Resumo: Estudo panorámico da fortuna crítica de Xosé María Díaz Castro. Analízanse os principais factores que foron conformando a recepción da súa obra. Identifícanse as achegas que máis influíron na interpretación da poesía do autor e estabelécense catro puntos de inflexión no proceso de recepción no período que vai da publicación de Nimbos á actualidade.

\begin{abstract}
This paper reviews the critical reception of Xosé María Díaz Castro's work. Relevant factors which shaped the reception of his work are examined, identifying those studies which most influenced the interpretation of his poetry, as well as four turning points regarding its reception from the publication of Nimbos to the present day.
\end{abstract}

Palabras chave: Xosé M. Díaz Castro, poesía galega contemporánea, recepción.

Key words: Xosé M. Díaz Castro, contemporary Galician poetry, reception.

Pensamos ser un libro de dura e influencia. Ha ser moitas veces descoberto. Moitos agardarán por il. Moitos sorprenderanse de nono ter escuitado. Todo quer o seu tempo. Ramón Otero Pedrayo.

\section{IDEAS LIMIARES PARA UNHA RECEPCIÓN EN CATRO TEMPOS}

A dedicatoria do Día das Letras Galegas a un escritor ou escritora estabelece desde hai anos un punto de inflexión na fortuna da súa obra. A incidencia, tanto espontánea como programada, da efeméride na recepción é un feito abondo coñecido cuxa análise reborda as dimensións deste traballo. A propia actualización do estado da cuestión, que complementa as levadas a cabo no seu día por Xesús González Gómez 
(1987) e, máis recentemente, pola coordinación do número XXIX dos Cadernos Ramón Piñeiro, dedicados a Díaz Castro (Cochón 2014), enmárcase no programa de actividades arredor das Letras.

O do escritor de Guitiriz é un caso singular no que á fortuna crítica se refire, se temos en conta tanto a condición de clásico que se lle vén atribuíndo como a recepción favorábel para xeracións vindeiras augurada, de maneira temperá, por Ramón Otero Pedrayo (1962) na cita reproducida a xeito de cabeceira. A exposición dunha panorámica da cuestión, articulada ao meu entender en catro tempos, debe retomar tres ideas abondo asentadas nos estudos literarios galegos, que enumero a seguir:

1. O poeta de Guitiriz vén gozando desde hai anos da condición de clásico á que se aludía máis arriba. Alén disto, vén sendo asociado a un só libro. Nimbos (1961) foi até o ano 2014 o único poemario seu coñecido e dispoñíbel.

2. Deixando a un lado recensións laudatorias, como a de Otero Pedrayo, aparecidas no momento da publicación de Nimbos, o recoñecemento de Díaz Castro foi serodio. Fóra dalgunhas excepcións, este remóntase á década dos oitenta do pasado século, momento no que xorden as primeiras reivindicacións e tamén os primeiros estudos favorecidos, sen dúbida, por un contexto estético máis afín.

3. Con independencia dos traballos aparecidos a partir deste período, Díaz Castro foi durante moito tempo identificado sobre todo cun poema, o celebérrimo "Penélope”. O seu verso "un paso adiante i outro atrás, Galiza” converteuse nun lema que forneceu retóricas diversas.

Malia demandaren oportunas matizacións, estas ideas serven para trazar unhas liñas vertebradoras da cartografía da recepción, pois apuntan tres momentos clave: o da publicación de Nimbos, o das reivindicacións do escritor e o das relecturas, principalmente feministas, do poema "Penélope". A eles habería que engadir o da celebración do Día das Letras Galegas para completar a cronoloxía da fortuna crítica do escritor.

\section{A PUBLICACIÓN DE NIMBOS}

A aparición de Nimbos suscitou, como se dixo, críticas eloxiosas que saudaban o libro facendo fincapé en dous elementos: a novidade e a orixinalidade. No que atinxe ao primeiro deles, algúns textos repararon no feito de se tratar da obra dun autor inédito, en boa medida descoñecido, que publicaba na súa madurez. A este respecto, cómpre lembrar que Díaz Castro non era, á altura de 1961, un escritor absolutamente descoñecido. Armando Requeixo (2001) encargouse de dar noticia dalgunhas composicións de preguerra, así como de exhumar, entre 
outros textos ${ }^{1}$, os poemarios Follas verdes (1934) e Follas ó aire (1935) (Díaz 2014b). Resultan polo tanto acertadas as palabras de Mario Regueira cando afirma que "Díaz Castro non representa a figura dun poeta inédito que publica unha obra sorprendente tendo case cincuenta anos" (2014: 254).

As primeiras recensións salientaron tamén a orixinalidade da voz do autor de Nimbos a pesar de certas afinidades con Noriega Varela, con Crecente Vega ou con Aquilino Iglesia Alvariño. Nos meses que seguiron á publicación do poemario, este recibiu valoracións entusiastas e contundentes de lectores como Xosé María Álvarez Blázquez, que considerou Nimbos "un libro de poesía verdadera, una obra importante de un nuevo poeta de Galicia, que se incorpora, con firmísimo paso, a las filas de nuestro lirismo" (1961). Ánxel Fole cualificouno de "autor con voz propia y canto propio", ao tempo que falou da ausencia na súa poesía de "ismos, modas y escuelas" (1961). Ramón Lugrís referiuse a Díaz Castro como "un extraordinario poeta" que "dende agora está chamado a figurar na lírica galega con todo-los dereitos que lle da a súa peculiarísima voz" (1961). Encomiástica foi tamén a recensión publicada por Ricardo Carballo Calero, quen, nunha liña próxima á de Otero Pedrayo na crítica máis arriba reproducida, auguraba: "Díaz Castro farase ler, aínda sendo poeta, neste instante da nosa cultura no que só acostumamos ler aos prosistas" (1961).

Unha revisión das primeiras lecturas de Nimbos non pode obviar a súa condición de críticas inducidas por parte dos editores de Galaxia, en especial de Francisco Fernández del Riego e de Ramón Piñeiro. Así o demostraron os responsábeis do volume Nimbos: cáliz fervendo! (2014), nunhas páxinas limiares que achegan un esclarecedor texto de prensa atribuído a Álvaro Cunqueiro no que este anuncia a inminente aparición do poemario de Díaz Castro:

La Editorial "Galaxia" anuncia como de inminente aparición un libro del poeta José María Díaz Castro, titulado "Nimbos”. El poeta, solamente conocido hasta ahora en círculos muy restringidos, dueño de una nostálgica voz en la que la sangre apasionada se vela con tenues brumas, sosegado en la soledad pero ahíto de vida interior se acerca por primera vez al gran público. Se trata de una aportación de excepcional calidad a la siempre riquísima lírica gallega [...]. (Cochón 2014: 9)

1 Trátase de textos publicados en La Noche, do tríptico Nascida d'un sono (1947), de poemas aparecidos na revista Alba e da composición incluída por Francisco Fernández del Riego na Escolma de poesía galega (1955), na sección dedicada a poetas que non tiñan obra publicada. 
A este clima favorábel non resultou alleo o feito de que Nimbos fose un libro animado e solicitado pola Editorial Galaxia, como explicou Mario Regueira (2014: 251 e ss.) nun estudo clarificador no que analizou ademais a importancia do poemario dentro da estratexia da editorial.

Non debe esquecerse tampouco o contexto estético no que viu a luz o libro de Díaz Castro, dominado pola poesía social. $\bigcirc$ texto máis representativo desta corrente, Longa noite de pedra, foi publicado un ano despois de Nimbos. O novo escenario estético e a popularidade acadada polo libro de Celso Emilio Ferreiro explican a defensa que do de Díaz Castro fixo Xosé María Álvarez Blázquez, ao alertar de que "estamos asistiendo al espectáculo del arte en plena deshumanización" e presentar, fronte a tal situación, o modelo de Díaz Castro como o de "un hombre humano -ya es preciso hacer este absurdo distingo-", dono dunha "poesía reflejo hirviente de tal humanidad" (1961). É este un dos moitos exemplos nos que se bota man da obra do escritor de Guitiriz como reacción contra a poesía social e os novos códigos estéticos.

Con excepcións, logo da recepción inmediata que se acaba de referir, a obra de Díaz Castro foi vítima do esquecemento durante os anos 60 e 70, por moito que o autor fose recoñecido por algúns dos seus pares, como demostrou Armando Requeixo (2013) recordando a súa presenza nos catálogos de poetas galegos do momento elaboradas por Xesús Alonso Montero ou Benito Varela Jácome. Con todo, unha das excepcións á actitude xeneralizada foi o artigo no que Xosé Luís Franco Grande denunciaba o feito de que "unha poesía de tantos quilates non soe e só en medios reducidos se lle dispense a atención que merece" (1964: 512). Na súa reivindicación identificaba a "falta de poder creador (anotemos isto ben) que se bota de ver na literatura do noso tempo", e a "crise de imaxinación creadora" que dela deriva, como as causas principais da infravaloración da poesía de Díaz Castro (1964: 512). O ensaio de Franco Grande é unha mostra dunha función correctora da crítica exercida tamén polos autores doutros comentarios que reaccionaban ante a ausencia do poeta nalgunhas antoloxías de posguerra. É o caso da nota na que Ramón Piñeiro se sorprende pola omisión de Díaz Castro en Poetas gallegos de posguerra de Basilio Losada (1972), ou da recensión na que Fernández del Riego critica a exclusión que do autor estudado fai Miguel González Garcés en Poesía gallega contemporánea (Lorenzana 1977)².

2 Vid. para isto Queixas 2014: 233 e ss. 


\section{OS ANOS OITENTA}

O denominado cambio de rumbo producido no xénero poético nos inicios da década dos 80 semellaba apuntar cara a un contexto estético máis favorábel para a recepción da poesía de Díaz Castro. A estética dominante, axiña canonizada como poesía dos oitenta e identificada con trazos como o regreso aos temas clásicos ou o coidado formal, presentaba unha maior afinidade coa do poeta de Guitiriz que os versos sociais escritos nas dúas décadas anteriores. Por outra banda, debemos tamén ter presente un feito, a miúdo esquecido, como é a incorporación neste momento da literatura galega aos currículos escolares, que demandou non só a produción de materiais senón tamén de canons.

Deste período datan algunhas achegas á lectura do poemario de Díaz Castro, como o artigo de Xosé Ramón Pena (1979) significativamente titulado "Nimbos e a nova poesía galega", ou as páxinas dedicadas por Xosé Luís Méndez Ferrín no seu estudo De Pondal a Novoneyra (1984), onde se estabelecen algunhas das claves interpretativas máis reiteradas en traballos sucesivos, tal é o caso da importancia da luz, a condición relixiosa ou a nostalxia do paraíso perdido.

Foi, con todo, o 25 aniversario da publicación de Nimbos a efeméride que deu lugar ao primeiro recoñecemento colectivo recibido polo escritor, que se materializou no volume Homenaxe a Díaz Castro (1987), promovido pola Asociación Cultural Xermolos de Guitiriz. O libro reúne estudos dedicados a diferentes aspectos da obra do escritor -a arquitectura de Nimbos, a relixión, a lingua poética, a recepción ou o papel da muller- e unha homenaxe dos poetas da Terra Cha -Darío Xohán Cabana, Fernán Vello, Manuel María, Margarita Ledo, Xesús Rábade e Antón Santamarinha Delgado-. A publicación marca un punto de inflexión na configuración dunha bibliografía sobre Díaz Castro -limitada aínda a Nimbos- que recolle algunha das cuestións analizadas nas décadas anteriores e estabelece claves principais da lectura da poesía diazcastriana, como o clasicismo, o carácter metafísico e relixioso, o paisaxismo e a reflexión sobre o ser humano.

É tamén na década dos 80 cando a revista Dorna convida o poeta a publicar nas súas páxinas, rescatándoo dun certo confinamento tanto persoal como editorial. Recordouno deste xeito Xosé Manuel Salgado, nun texto publicado no número co que a revista lembraba o poeta con motivo do seu falecemento en 1991:

estivo sempre entre os nosos cometidos o de tentar recuperar algúns nomes confinados nunha nota a pé de páxina nas historias da Literatura máis acreditadas. E un deses nomes, relegado ó case absoluto esquencemento, é o de Xosé María Díaz Castro, rescatado do ostracismo a partir do número 6 da nosa revista. (1991: 23) 
A recuperación do poeta como escritor activo, que publica os seus versos á beira de voces nalgún caso noveis, non debe pasar desapercibida en calquera achegamento á recepción da súa obra, tendo en conta ademais o papel que a revista tivo na difusión da poesía que se estaba a escribir naquela altura (Nogueira 2006).

\section{AS RELECTURAS DE “PENÉLOPE”}

A fortuna da composición "Penélope" percíbese tamén na atención que suscitou nos estudos dedicados á poesía do autor. $\bigcirc$ poema foi obxecto de numerosas análises, que non é este lugar para compilar, e entre as que sobrancea, polo seu carácter canonizador, a levada a cabo por Claudio Rodríguez Fer (1989). Existe consenso entre a crítica á hora de recoñecer que a popularidade do texto diazcastriano garda unha estreita relación coa tematización metafórica e reinvindicativa nos seus versos dunha Galicia inmobilizada, que tan ben engarzaba na poesía de corte social. Esta dimensión, cuxo peso en Nimbos é menor ao doutras e que pasou desapercibida para os críticos do entorno de Galaxia aos que máis arriba me referín, foi posta de manifesto por Ricardo Carballo Calero en 1974, nuns termos que resultan abondo elocuentes a respecto do desinterese que a poesía social comezaba a suscitar naquela altura:

ao motivo do destino da comunidade en que o poeta se inserta o penelopiano destino de Galicia, un paso adiante e outro atrás. Así que Díaz Castro é tamén un poeta social. Só que non ten vocación de demagogo, polo que a súa poesía é non normativa. Quero dicir que o poeta non é un activista que se sirva da estrofa como da botella de gasolina. (1974: 277).

A imaxe "un paso adiante i outro atrás", que sintetiza esta dimensión social, deu lugar a unha das metáforas máis fértiles sobre Galicia, capaz de transcender o ámbito do literario para infiltrarse noutros discursos públicos.

Non é tanto o interese deste traballo reparar na produtividade da imaxe como no feito de que fose o poema de Díaz Castro un dos textos matrices na reescritura do que se denominou unha xenealoxía mítica (González Fernández 2005) baseada na figura de Penélope. Tal reescritura, que enlaza coa composición rosaliana "Tecín soia a miña tea" ${ }^{3}$, acada unha significación inequivocamente feminista a partir do poema titulado tamén "Penélope" ${ }^{4}$, de Xohana Torres. O texto conclúe cunhas

3 Da sección "As viudas dos vivos e as viudas dos mortos", de Follas novas (1880).

4 Do libro Tempo de ría (1992). 
palabras nas que a muller que agarda desafía o seu destino: "EU TAMÉN NAVEGAR". O verso acabou converténdose nunha consigna para as novas escritoras que, desde os primeiros anos da década dos noventa, estaban a construír a súa voz desde unha clara conciencia de xénero.

A reescritura poética de Penélope, que deu lugar a unha das xenealoxías máis fértiles creadas polas poetas galegas (Blanco 1995, González Fernández 2005, Nogueira 2006), partiu da contestación feminista de Xohana Torres a reformulacións anteriores, en particular, a dous poemas que transmitían o mito desde un punto de vista patriarcal: "Penélope", de Díaz Castro e "Pende en que pende, Penélope pensativa" ${ }^{5}$, de Álvaro Cunqueiro. $O$ texto do poeta de Guitiriz actuou polo tanto como modelo dunha das series máis celebradas da poesía galega contemporánea, o que constitúe tamén un interesante fenómeno de recepción.

\section{AS LETRAS GALEGAS DE DÍAZ CASTRO}

Sen ser este lugar para unha análise -por outra banda, necesaria- do Día das Letras Galegas desde o punto de vista da recepción das figuras homenaxeadas, creo oportuno recordar que un dos obxectivos da efeméride é a difusión da obra destes. No caso de Xosé María Díaz Castro, autor até o momento dun único libro, as Letras Galegas favoreceron a publicación da súa obra completa, que incluía os poemarios de preguerra inéditos máis arriba mencionados. A Poesía galega completa (Díaz 2014b) ofrece un material que os estudos elaborados de aquí en diante non poderán obviar e que obrigará a redimensionar a figura de Díaz Castro na literatura galega contemporánea.

A produción xurdida a raíz do Día das Letras Galegas, da que o presente texto forma parte, achegou ademais os estudos Vida e obra de Xosé María Díaz Castro (Requeixo 2013), A ferida da beleza en Nimbos (Pérez López 2014), así como a edición de facsímiles (Blanco/Salgado 2014) e composicións traducidas polo poeta, e compiladas no volume Cartafol de traducións e outros poemas (Díaz 2014a).

Os estudos aparecidos ao abeiro das Letras consolidaron a diversificación de liñas de análise ás que a obra de Díaz Castro fora sometida e contribuíron á tarefa de situar esta, con máis precisión, na poesía galega da posguerra. $\bigcirc$ ton reivindicativo que acompañou os estudos sobre o escritor de Guitiriz até comezos dos anos noventa foi polo xeral desaparecendo, o que debe interpretarse como un sinal de normalidade na recepción do escritor.

5 Composición pertencente a Herba aquí e acolá (1980). 
Estamos, con todo, diante dun ciclo incompleto que demanda, para o seu estudo, unha maior distancia temporal. Se os traballos aparecidos ao longo deste ano van reverter nun mellor coñecemento da obra de Díaz Castro, queda por saber como vai asimilar o campo literario galego estas achegas e como se verán reflectidas nun instrumento canonizador por excelencia como son as historias da literatura que están por escribir. As palabras de Ramón Otero Pedrayo, certeiro na súa intuición de que Nimbos había ser un libro "de dura e influencia" e "moitas veces descoberto", resultan tamén oportunas para pechar esta panorámica, dado que "todo quer o seu tempo".

\section{REFERENCIAS BIBLIOGRÁFICAS}

Álvarez Blázquez, Xosé María (1961): "Nimbos, un libro luminoso", Faro de Vigo 15/X/1961.

Blanco, Carmen (1995): Mulleres e independencia. Sada: Ediciós do Castro.

Blanco, Carmen e Xosé Manuel Salgado (eds.) (2014): Día das Letras Galegas 2014.

Xosé María Díaz Castro. Santiago de Compostela: Universidade.

Carballo Calero, Ricardo (1961): "Un poeta legible”, Faro de Vigo 20/X/1961.

(1974): "Figuras representativas da literatura galega", Grial 45, 269-279.

Cochón, Luís (2014): “Adro”, en Luís Cochón (ed.), Nimbos: cáliz fervendo! Cadernos Ramón Piñeiro XXIX. Santiago de Compostela: Centro Ramón Piñeiro para a Investigación en Humanidades, 9-17.

Díaz Castro, Xosé María (2014a): Cartafol de traducións e outros poemas. Santiago de Compostela: Consello da Cultura Galega. Edición de Armando Requeixo. (2014b): Poesía galega completa. Vigo: Galaxia. Edición de Armando Requeixo.

Fole, Ánxel (1961): "Un nuevo poeta”, Faro de Vigo 17/II/1961.

Franco Grande, Xosé Luís (1964): “Díaz Castro nesta hora”, Grial 6, 512-518.

González Fernández, Helena (2005): Elas e o paraugas totalizador. Escritoras, xénero e nación. Vigo: Edicións Xerais de Galicia.

González Gómez, Xesús (1987): “Díaz Castro perante a crítica”, en Homenaxe a Xosé Ma Díaz Castro. Guitiriz: Asociación Cultural Xermolos, 57-64.

Lorenzana, S. [Fernández del Riego, Francisco] (1977): "Poesía gallega de posgue-

rra. Antología bilingüe, por Miguel González Garcés”, Grial 55, 125-126.

Lugrís, Ramón (1961): "Notas a Nimbos", La Noche 9/XI/1961.

Méndez Ferrín, Xosé Luís (1984): De Pondal a Novoneyra.Vigo: Galaxia. 
Nogueira Pereira, María Xesús (2005): "A embarcación de palabras. Pequena crónica da revista Dorna", en Ana Isabel Boullón Agrelo, Xosé Luis Couceiro Pérez e Francisco Fernández Rei (coords.), As tebras alumeadas. Estudos filolóxicos ofrecidos en homenaxe a Ramón Lorenzo. Santiago de Compostela: Universidade, $587-598$.

(2006): "De vangardas e Penélopes. A intertextualidade na poesía galega dos noventa”, Madrygal. Revista de estudios gallegos 9, 93-102.

Otero Pedrayo, Ramón (1962): "Nimbos, de Díaz Castro", La Noche 11/I/1962.

Pena, Xosé Ramón (1979): “Nimbos e a nova poesía galega”, La Voz de Galicia 23/ $\mathrm{XI} / 1979$.

Pérez López, Segundo Leonardo (2014): A ferida da beleza en Nimbos de Xosé María Díaz Castro. Santiago de Compostela: Instituto Teológico Compostelano.

Piñeiro, Ramón (1972): "Poetas gallegos de posguerra, por Basilio Losada", Grial 35, 111-112.

Queixas Zas, Mercedes (2014): "Unha necesaria actualidade retrospectiva", en Luís Cochón (ed.), Nimbos: cáliz fervendo! Cadernos Ramón Piñeiro XXIX. Santiago de Compostela: Centro Ramón Piñeiro para a Investigación en $\mathrm{Hu}$ manidades, 231-247.

Regueira, Mario (2014): "Entre Deus e a Terra. Xosé María Díaz Castro no proxecto de Galaxia”, en Luís Cochón (ed.), Nimbos: cáliz fervendo! Cadernos Ramón Piñeiro XXIX. Santiago de Compostela: Centro Ramón Piñeiro para a Investigación en Humanidades, 251-267.

Requeixo, Armando (2001): “Xosé María Díaz Castro poeta de preguerra”, Madrygal. Revista de estudios gallegos 4, 99-109.

(2013): Vida e obra de Xosé María Díaz Castro. Vigo: Galaxia.

Rodríguez Fer, Claudio (1989): “O poema «Penélope», de Díaz Castro”, en Poesía galega. Crítica e metodoloxía. Vigo: Edicións Xerais de Galicia, 199-210.

Salgado, Xosé Manuel (1991): "Díaz Castro e Dorna. A creba dun silencio”, Dorna $17,23-32$.

VV. AA. (1987): Homenaxe a Xosé Ma Díaz Castro. Guitiriz: Asociación Cultural Xermolos. 